\section{High Levels of Phosphorus and Die-Back in Yellow Lupins}

IN a rotation experiment ${ }^{1}$ with conifers and green crops in a Forestry Commission nursery on very acid heathland soil near Wareham, Dorset, yellow lupins Lupinus luteus grown with fertilizer have often shown signs of die-back in the older leaves, occasionally with more extensive damage leading to the death of the whole plant.

In the early stages of the symptoms the leaflets become incurved, and death of the tissue starts near the tip of the leaves and proceeds inwards from the edges. In the final stages the leaflets turn grey and drop. Sometimes translucent patches and small brown spots have been noticed before the more severe symptoms set in.

Samples of plants, both healthy and affected, were obtained for chemical analysis from a number of plots at Wareham nursery that had been treated with fertilizer. The percentages of nitrogen and potassium seemed normal for young plants, but the phosphorus values in those affected were abnormally high, reaching $2 \cdot 2$ per cent phosphorus in dry matter for the most severely affected plants (Table 1).

Table 1. Phosphores Contents of Healthy and Afrected Yockg LTPINS, WAREHAM, 1958

$$
\begin{array}{cc}
\begin{array}{c}
\text { dry weight } \\
\text { per plant }(\mathrm{gm} .)
\end{array} & \begin{array}{c}
\text { Phosphorus in dry } \\
\text { matter of plant } \\
\text { (yer cent) }
\end{array} \\
0.7 & 0.6 \\
0.5 & 1.7 \\
0.4 & 2 \cdot 2
\end{array}
$$

Plant, healthy .

Leaflets with severe die-back

The possibility of phosphorus toxicity was examined in a pot experiment at Rothamsted using Wareham soil and testing five levels of application of monocalcium phosphate (0-64 mgm. phosphorus per plant). Monocalcium phosphate was used because it is the

\begin{tabular}{|c|c|c|c|}
\hline $\begin{array}{l}\text { Phosphorus } \\
\text { applied per } \\
\text { plant (mgm.) }\end{array}$ & $\begin{array}{l}\text { Visual 'score' } \\
\text { for amount } \\
\text { of die-back }\end{array}$ & $\begin{array}{l}\text { Dry weight } \\
\text { per plant } \\
\text { (gm.) }\end{array}$ & $\begin{array}{l}\text { Phosphoris in dry } \\
\text { matter of plant } \\
\text { (per cent) }\end{array}$ \\
\hline none & 0 & $1 \cdot 6$ & $0-16$ \\
\hline 8 & 1 & 1.7 & 0.53 \\
\hline 16 & 3 & $1 \cdot 6$ & $1 \cdot 10$ \\
\hline 32 & 6 & $1 \cdot 2$ & 1.76 \\
\hline 64 & 10 & 0.7 & 1.98 \\
\hline
\end{tabular}
essential constituent of superphosphate which had been applied in the nursery. All pots received basal dressings of nitrogen, potassium, calcium and magnesium. Table 2 shows the visual score for damage, dry weight and phosphorus content of the plant.

The degree of damage increased with the amounts of phosphorus applied and with the phosphorus contents of the plants. At the highest rate of phosphorus with a visual 'score' for damage of 10 , all except two or three of the youngest leaves were dead or dying.

Damage is slight when the phosphorus content of the leaves is less than 1 per cent, but so severe at 2 per cent that the lupin plants ultimately die. The results of this pot experiment confirm the suggestion that the plants grown at Wareham nursery were suffering from excess of phosphorus.

At another nursery, near Oxford, yellow lupins grew normally when given the same fertilizer treatment as at Wareham. The soil at Oxford, however, was a sandy loam and less acid. Although the differences in the soils of the two nurseries may account in part for the differences in the effect of application of phosphorus fertilizer, sitka spruce and other conifer seedlings not only show no damage on the Wareham soil but growth is increased by superphosphate applied at comparable rates. Sitka spruce seedlings take up less phosphorus than the lupins; the level of phosphorus in the plant is only about 0.3 per cent, and this is little affected by varying the rates of superphosphate. Rossiter in Australia ${ }^{2,3}$ found that subterranean clover and oats grown on certain sandy soils had high concentrations of phosphorus and that the plants were also damaged.

As our results show striking differences, not previously reported for the United Kingdom, between the behaviour of different crops and soils, more detailed experiments are planned.

The experiments were part of an investigation done in collaboration with the Research Branch of the Forestry Commission.

\section{R. G. WARREN}

B. Benzian

Rothamsted Experimental.Station, Harpenden, Herts. June 1.

1 Benzian, B., J. Sci. Food Agric. (in the press). ${ }^{2}$ Rossiter, R. C., Aust. J. Agric. Res., 3, 227 (1952) s Rossiter, R. C., Aust. J. Agric. Res., 6, 1 (1955).

\section{A Quick Method for Extracting Plant Embyros from Certain Types of Seed}

ONE of the most difficult problems in the culture of plant embryos is to find a satisfactory way of extracting the embryo from the seed without damage and in such a manner that both embryo and culture medium remain sterile. This is particularly difficult if the seed coat is very hard, and usually dissection under sterile conditions is the standard method employed ${ }^{1,2}$. The following technique was originally evolved to provide an easy method for extraction of mature Paconia embryos from their seeds, and has since been used in the removal of embryos from other hard. coated seeds.

The dried seeds are first soaked until fully hydrated. They are then immersed for $30 \mathrm{~min}$. in concentrated sulphuric acid, thoroughly washed in running water for at least $1 \mathrm{hr}$., and incubated in water overnight at $35^{\circ} \mathrm{C}$. After incubation they are surface dried. A gentle pressure on the seed between the fingers will cause the embryo to be extruded through the micropyle. The embryo may thus be squeezed directly on to the agar culture slope in a few seconds with virtually no danger from contamination from the atmosphere. The embryos subjected to this treatment are viable in every way and commence to develop almost immediately.

The extraction technique can also be used on mature seeds of Nuphar and Nymphoea species. The embryos of these plants are contained within the seed in a small sphere of endosperm which lies just beneath the operculum and is embedded in perispermie tissue ${ }^{3}$. After incubation the opereulum is readily removed and gentle pressure causes the entire endosperm sphere to emerge. The embryo can be easily extracted from this without damage as the endosperm tissue is very soft.

The time necessary in acid will vary according to the species and must be initially determined for each. It is largely dependent upon the size of the seed and the nature of the testa. Generally, the larger the seed, the longer the period that is necessary. The time spent in running water should not be reduced as this may affect the subsequent viability of the embryos. 